\title{
Where and how do young People Like to Get their Sexual and Reproductive Health Information? Experiences from Students in Higher Learning Institutions in Tanzania: A Cross-sectional Study
}

Ruby Doryn Mcharo ( $\nabla$ mcharo7@hotmail.com )

National Institute for Medical Research https://orcid.org/0000-0002-5006-3275

Philippe Mayaud

London School of Hygiene \& Tropical Medicine

Sia Emmanueli Msuya

Kilimanjaro Christian Medical College: Kilimanjaro Christian Medical University College

\section{Research article}

Keywords: Sexual and Reproductive health, parent-child communication, young adults, adolescents, sexual behavior, Tanzania

Posted Date: November 17th, 2020

DOI: https://doi.org/10.21203/rs.3.rs-105796/v1

License: (c) (i) This work is licensed under a Creative Commons Attribution 4.0 International License. Read Full License 


\section{Abstract}

\section{Background}

Sexual and reproductive health (SRH) among young adults in developing countries is still a major public health concern. Early school-based sexuality education programs and sexual health information sharing between teachers, parents and young people have been considered protective against sexual health risks that young people are prone to. There is limited information on preferred choices of "where" and "how" young people like to get their SRH information. Here, we describe what young people prefer to learn with regard to sexual matters, where and who they prefer to learn from, and their experiences of parent-child sexuality communication.

\section{Methods}

This was a cross-sectional study, conducted from March 2019 to January 2020 among students aged 18-24 years attending Higher Learning Institutions (HLIs) within Mbeya. A self-administered questionnaire was used to collect information on SRH education, ability to discuss sexual matters with a parent/guardian, and SRH information gap during early sexual experience.

\section{Results}

Out of 504 students that were enrolled, 377 (74.8\%) reported to be sexually active with mean age at sexual debut of 18.4 years. Six out of ten students found it difficult to discuss or did not discuss sexual matters with a parent/guardian while growing up at age 12-18 years. Majority learnt about SRH matters from peers $(30 \%)$ and lessons at schools $(23 \%)$. We found a gender-biased preference on sexual matters discussions, such that female and male participants preferred discussions with female adults and male adults, respectively. Peers (18\%), Media (17\%) and schools (13\%) were preferred sources of SRH information. On recalling first sexual experience, participants felt they needed to know more about sexual feelings, emotions and relationships (26.9\%), safer sex (13.8\%), how to be able to say 'No' (10.5\%) and how to use a condom correctly $(10.2 \%)$.

\section{Conclusion}

Young people have a gender-biased preference when it comes to learning about SRH matters from their parents; however, such conversations seldom occur. Community health IEC should incorporate the agenda on building skills of parents on parent-child communication on sexual matters so as to empower them to confidently initiate and convey appropriate and sufficient sexual health information. Comprehensive SRH education and skills building is needed in the current school SRH curriculum in order need to meet the demand and needs of students' and teachers'.

\section{Background}

Sexual and Reproductive health (SRH) among young adults in developing countries is still a major public health concern (1). The World Health Organization (WHO) estimates that one out of twenty adolescents contract a Sexually Transmitted Infection (STI) each year (2). Almost half of new HIV infections are accounted for among the 15-24 years age-group, identifying this group as high-risk (2). In Sub-Saharan Africa (SSA), one in six adolescent deaths are attributed to HIV (3). In Tanzania, 45\% of new HIV infection cases are reported among young adults, with less than half of the population aged 15-24 years being accurately informed on HIV/AIDS $(4,5)$. Following vast campaigns on STIs and HIV/AIDS, a number of studies on sexual practices among young adults in developing countries still show suboptimal levels of the necessary preventive behavior against HIV, STIs, unwanted pregnancies and injuries (6-8). Consequences of risky sexual activity among young adults include unwanted pregnancies, unsafe abortions, risk for STIs which may be asymptomatic with long-term effects, and increased risk of getting HIV (2).

Early school-based sexuality education programs and sexual health information sharing between teachers and young people have been considered protective against sexual health risks that young people are prone to $(9,10)$. Schools are reliable frameworks linking young people and their communities, preparing them during the transition to adulthood; and young people look up to their teachers as a preferred, reliable and integral point when it comes to learning about sexual matters $(11,12)$. An evaluation of sex and HIV education programs in developed and developing countries among youth in schools and community settings, found such programs being more likely to influence a positive impact on delaying sex, reducing number of sexual partners, increase in condom and contraceptive use, as well as composite measures of sexual risk reduction (9). In Tanzania, a number of programs targeting adolescents and young people, in and out-of-school, have been put in place to promote SRH $(13,14)$. However, such programs have proved beneficial in improving SRH knowledge among young people, but have less effect on improving safer sexual behaviours (15).

Parents is another group that have key role in informing and educating adolescents and youths on matters pertaining to SRH, in addition to their responsibility of assuring optimal growth and developmental well-being of their children. Similar to school-based sexuality education programs, parent-child communication can encourage preventive behaviors against risky sexual behaviors among young people (16-18). Parents can impact moral, cultural values, positive beliefs and skills in order to empower adolescents to make correct decisions and reduce their risk to sexual health threats. Studies have shown that young people also prefer parent-child communication with regard to SRH matters but such important conversations do not happen in many settings in SSA (18-20). Healthrelated behaviors, such as sexual activity, are determined by different players within a defined institution; and the key players define meanings and level of acceptance as to the how, who and when (21). Such meanings then influence decision-making among individuals, example of young adults, on matters of sexual behaviors and health care seeking and practices. Sexual behavior is thus an outcome of a variety of factors varying from personal, peer, parents, institutional, societal and even public policies.

In Tanzania, studies have noted that the school SRH curriculum lacks enough resources and that students reported school curriculum as an inadequate source for sexual health matters and opt for other sources (peers, media, and parents/relatives) (22). Young people are thought to receive information on sexual 
matters from uninformed sources such as their peers or social media; and their will to take preventive actions may be challenged by barriers or modifying factors towards prevention or treatment of the disease. The curriculum faces a number of limitations, such as the students' age when commencing the curriculum in relation to the reported age at sexual debut and ineffective inclusion of sensitive sexuality matters $(23,24)$. Young people reported curriculum gaps on sexual decision-making, sexual pleasure, relationships, safer sex and condom use, and masturbation (24). Misconceptions about level of perception to sexual health risks may result from ignorance as a result of lack of comprehensive sexual education from an early age (example secondary or high school). Gender and sexuality attitudes and values are believed to start being established early in childhood and through adolescence, and eventually dictate sexual behavior and continue to affect the individual through adulthood.

Lack of proper SRH education reflects problems facing young people such as unprotected sex, unplanned pregnancies with unsafe abortions, HIV/STIs (1, 2). Additional to school-based sexuality education programs and parent-child communication, other avenues for learning may include information sharing with peers, media, newspapers, Internet, and/or health personnel and facilities. In Tanzania, there is limited information on preferred choices of "where" and "how" young people like to get their SRH information. This study aimed to describe what young people prefer to learn with regard to sexual matters. Additionally, we focus on where and who they prefer to learn from, and their experiences of parent-child sexuality communication. We refer to sexual matters as sexual activities, sexual identity, sexual interests, sexual orientation, sexuality, sex and sexual relationships.

\section{Methods \\ Study design and site}

This was a cross-sectional study conducted from March 2019 to January 2020 in Mbeya region, Tanzania. Mbeya is located within the Tanzanian Southern Highlands Zone and it borders Zambia and Malawi, internationally. The region comprises of a youthful population with 6 High Learning Institutions (HLIs) registered by the Tanzania Commission for Universities (TCU) during the study period, namely Mbeya University of Science and Technology (MUST), Mzumbe University - Mbeya University College (MUMCo), Tanzania Institute of Accountancy (TIA), Mbeya Teofilo Kisanji University (TEKU), Open University (OUT) and St. Augustine University of Tanzania (SAUT).

\section{Population, sample size and sampling}

Participants were enrolled from HLIs within Mbeya region in any year of study, if they were Tanzanians, aged 18-24 years and agreed to provide written informed consent prior to all study-related procedures. Participants were ineligible to take part if they were students attending short-term courses (< 6 months) or elective students.

Proportions assessment in cross-sectional studies using random sampling was used to estimate sample size adjusted for non-response, and the minimum sample required was 494 .

\section{Sampling}

Each HLI in Mbeya region was invited to participate and all the HLIs agreed to take part but Open University did not have students that were eligible because they were older than 24 years. A complete electronic list of all students registered, aged 18-24 years of age was obtained from the Academic Registrars' offices. Probability proportional to size was used to determine the total number of students by sex from each HLI due to the different number of students from each HLI. A computerized random number was used to select students irrespective of the course they were registered for. Each selected eligible participant was notified via phone that he/she has been randomly selected to take part in the study and if he/she was willing to take part, he/she was then requested to report to the data collection point within their respective campuses. If the phone number was not reachable or the selected participant had no mobile phone, the class representative assisted to physically find the selected participant and a face to face appointment was scheduled. Each selected participant was required to present a student identification proof before study procedures could commence.

\section{Data collection methods, tools and study procedures}

The study team used an individual self-administered questionnaire using a tablet or smart phone through a web-based software (ODK) or hard copy, which ever method the participant preferred. Pre-testing of the questionnaire was done on few HLI students from a nearby region prior to data collection; and any emerging issues from the pre-testing were factored in to revise the questionnaire in a more practical manner. The questionnaire was divided into sections, and collected information on socio-demographics (age, religion, marital status, year of study at HLI, highest academic level before current $\mathrm{HLI}$, type of secondary school attended, permanent residence and source of financial support); Sexual and Reproductive health (ability to discuss sexual matters with a parent/guardian, learning about sexual matters and Sexual and Reproductive health information gap during early sexual experience). Parent-adolescent communication and preference of source of SRH information was assessed using a set of 10 questions.

\section{Data management and statistical analysis}

The web-based software (ODK) was designed with smart checks for incomplete or ambiguous responses, and responses through the hard copy questionnaire were reviewed for completeness at the end of each day by the Research Assistant. Data was cleaned and analysed using statistical software Stata version 14 for Windows (Statacorp, College Station, TX 77845, USA). Data was summarised descriptively using percentages and/or proportions for categorical variables, mean and respective measure of dispersion for numerical variables. Missing data were addressed as "Not reported".

\section{Results}




\section{Response}

A total of 632 students aged 18-24 years attending HLIs in Mbeya were sampled randomly and were eligible to participate; and of those, 504 students were enrolled. Of the 128 who didn't participate, $32(25 \%)$ could not be reached and the remaining were not willing to participate in the study.

\section{Characteristics of the participants}

Participants' socio-demographic characteristics are shown in Table 1. The mean age of the 504 students was 21.5 years (SD 1.7), with more than half of the participants being males (56.9\%), single (93.8\%), and supported financially by a parent/guardian (86.3\%). Majority of the participants (78.0\%) were in their first or second year of study. Other background characteristics are shown in Table 1 . There were no reports from 14 (2.8\%) participants on Religion, and 1 ( $0.2 \%)$ on Place of residence.

\section{Learning about Sexual and Reproductive health matters}

Over seventy percent of the participants lived with both parents while growing up at the age of 12-18 years as shown in Table 2. Proportion of participants that found it difficult to discuss or did not discuss sexual matters with a parent/guardian at age 12-18 years was 61\%, similar between female and male participants. Two of the common source where participants learnt about SRH matters while growing up was friends of about their similar age group (30.2\%) and lessons at schools (22.7\%), respectively. Female participants (47.5\%) preferred discussing sexual matters with female adults while male participants (42.9\%) preferred male adults. As shown in Table 2 about $70 \%$ of the participants had received a Sexual and Reproductive health Education (SRE) while in secondary school (O' Level) and $52.8 \%$ only while at University.

\section{Sexual and Reproductive health information gap during sexual debut}

Of the 504 enrolled participants, 377 (74.8\%) reported to be sexually active. While recalling first sexual experience, $35.8 \%$ of the 377 participants mentioned they were in love, $28.1 \%$ got carried away and $16.7 \%$ were just curious, Table 3 .

When asked from whom they would have liked to learn more on SRH matters that they knew little about at time of sexual debut; $18.0 \%$ said they would like to learn from friends, $17 \%$ wanted to learn from Media/Books/newspapers/Internet/pornographic websites and 13\% from lessons at school, Table 3. Parents ranked 4th and 5th as source of SRH at time of debut. If diagnosed with an STI, participants would rather tell a family member (48.3\%) or sexual partner (53.6\%) than other people.

Figure 1 shows what participants would have liked to know at time of sexual debut; $26.9 \%$ said they wished they knew about sexual feelings, emotions and relationships, $13.8 \%$ on safer sex, $10.5 \%$ on how to be able to say 'No' and $10.2 \%$ on how to use a condom correctly.

\section{Discussion}

Findings from the study among 18-24 year old students attending HLIs in Mbeya-Tanzania showed that three-fifth of the participants found it difficult to discuss or did not discuss sexual matters with a parent/guardian while growing up at age 12-18years; and majority learnt about SRH matters from friends of about their similar age group and lessons at schools. Young people also report on gender-biased preference on sexual matters discussions among family members, such that female and male participants preferred discussions with female adults and male adults, respectively. About seven in ten students received a SRE while in secondary school (specifically O' Level) and just over a half of the participants (52.8\%) while at University. Recalling their first sexual experience, participants felt they needed to know more about sexual feelings, emotions and relationships ( $26.9 \%)$, safer sex (13.8\%), how to be able to say 'No' $(10.5 \%)$ and how to use a condom correctly (10.2\%). Students reported they would prefer to learn SRH issues first from friends, media and schools.

In this study, 6 out of 10 participants found it difficult or did not discuss sexual matters at all with their parents while growing up. Additionally, parents were not mentioned in the topmost common sources where participants learnt about sexual matters while growing up from age 12 . Contrast to our findings, in a study on the use of reproductive health information among university undergraduates in Nigeria, more than half of the respondents mentioned parents, relatives, and health workers as their main source of health information (25). Similar to our findings, other studies in South Africa and Tanzania have also reported on the lack of or insufficient communication on sexual matters between parents/guardians and their children (19, 20, 23). Such observations may be due to cultural differences in African settings, such that other cultures and traditions do not entertain parents educating their children about SRH matters. Comparable to SRH lessons at school, parent-child communication can actively promote desirable preventive behaviors against sexual health threats among young people. As with other developmental and behavioural aspects that parents/guardians can advocate among their young ones, sexual behaviour and attitudes towards sexual health can also be learnt and influenced at the household/family level. Programs advocating parent-child communication and SRH among adolescents/young adults need to factor in enhancing parents' communication skills regarding sexuality matters, self-efficacy as well as appropriate SRH knowledge.

Many times young people start discovering and learning primarily about sexual issues from their peers and/or sexual partners, as reported in our findings. In the process of growing up, there is a flexible shift of emotional bonds from parents/guardians to peers to sexual partners (26). Times when these emotional bonds peak are also likely to be convenient learning times on sexual matters; and parents often have the initial and most crucial stage and are at an added advantage. It is important to understand that adolescents and young adults go through a "transition phase" whereby the family can not quite define them as children or yet adults (26), and this is a period when the habitual position of the parents/guardians may get overridden slowly by peers/friends of a similar 
age. In situation where parents/guardians do communicate about sexual matters, then talks or conversations have been known to either be threatening, authoritative, subjective to an already existing incidence $(27,28)$, triggered through examples of acquaintances who suffered STIs/HIV or messages from radio/TV programs (19). Unfavourable methods of parent-child communication about sexual matters are confusing and rarely successful in modifying behaviour of adolescents/young adults who are highly experimental and "fragile". In a qualitative exploration of sexual health by Kajula et al., parents were likely to use fear to discourage unpleasant sexual behaviours among their children and children noted that sexual health conversations with parents were unclear and just full of warnings and dangers of HIV/STIs (19).

Parents/guardians may face challenges when it comes to speaking to young adults on sexual matters as they may lack sufficient knowledge (28) or some may believe that sharing SRH information will encourage sexual practices among their children (29). Evening or weekend radio/TV programs could usefully be used to set off such family talks as in most urban and some rural African settings, parents/guardians after work would sit with their children to unwind while watching news or comedy shows. In African settings during the old times, the community would have a scheduled time for adolescents/young adults to meet with community or family elders (respectable distinguished males or females) who would take them through information on sexual matters and the culture of being able to postpone sexual encounters until when deemed appropriate. In recent years times have changed and due to urbanization, many of such cultures have disintegrated (30) and the family structure is left to operate on its own. It is therefore important, now than ever, for parents/guardians of adolescents/young adults to be able to speak up friendly, calmly, clearly and fearlessly about sexuality and sexual matters with their children.

Adolescent/young adults prefer to talk to their parents/guardians as evident from our findings and those reported elsewhere (19, 20, 27), but important to note that there is a gender-biased preference on such $(20,28,31)$. Additional to their peers, female children would prefer to speak to their mothers, while male ones with their fathers. It is valuable to understand why parents/guardians cannot speak with their adolescents/young adults, and vice versa. Parents/guardians need to recognize and accept that it is also their responsibility to protect their children against sexual health risks which they are prone to, and that this is not a responsibility referred to teachers or health care workers or their children's peers. Adolescents/young adults may experiment on risky sexual behaviours and not seriously perceive the health threat, either because of having poor sexual health information $(2,32)$ and/or limited access to SRH care $(2,5,33)$ and be at risk for STIs and/or HIV.

From our findings, three-quarter of the participants report to have received a SRE while in school and majority during O' Level secondary education; and of those who were already sexually active, looking back at their first sexual experience, majority thought they should have waited. Further, participants felt they needed to know more about sexual feelings, emotions and relationships, safer sex, how to be able to say 'No' and how to use a condom correctly; such information may indicate that during such an encounter probably even a condom or other protective means to STIs/HIV and/or pregnancy were not used. The SRE curriculum that was introduced in Tanzania in primary schools during early 2000's in response to the control of HIV epidemic has been important for adolescents in primary and secondary schools, but the challenge is the inability of some of the teachers to deliver the message and topics clearly (34). Mkumbo (2012) showed majority of urban and rural teachers are in favour of teaching SRE (12), but Cardoso and Mwolo noted ineffective inclusion of sensitive sexuality matters in the school curricula (34). Such curriculums lack enough resources and the students do not appreciated much the school as a tutor for sexual health matters. Introduction of SRE earlier on in life carry considerable benefits of delayed sexual intercourse, addressing misconceptions, preventing risky sexual behaviours and eventually STIs and/or HIV $(2,35)$.

School-based sexual health education has been found effective in relation to STI-related outcomes and is highly recommended worldwide (36, 37). On the contrary, evaluations of curricula in sub-Saharan Africa have been inconclusive on their impact towards risky sexual behaviours and reducing STIs incidence among young adults $(36,38)$. In a study done in Dar-es-salaam-Tanzania among adolescents on timing of sexual initiation, a larger proportion (35.6\%) of students reported communicating about HIV and sex with teachers and only $26.9 \%$ with parents (39). Delayed sexual initiation was significant among students who communicated with teachers, and authors acknowledged teachers' effective role in exploring HIV and sexual matters with young people. Subsequent to parents, teachers through SRE given in schools, play a vital role in shaping sexual behaviour among young people that is preventive against STIs and/or HIV $(14,36,40)$.

In this study, peers, lessons at schools and media were identified as key sources of SRH information and overall sex education. Additionally, we report findings that young adults who claim to have received the SRE, and have already experienced sexual encounters needed to know more about sexual feelings, emotions, relationships, safer sex practices and ability to turn down a sexual encounter. It is crucial to understand whether the SRE curricula indeed cover the "sexual" aspect. Could it be that the "sexual" aspect is missing from the SRE? Could it be that teachers are still not comfortable to teach such sensitive issues considering our culture that may label such topics as taboo? Nearly a decade after Mkumbo's work on teachers' attitudes towards and comfort about teaching school-based SRE in urban and rural Tanzania (12), it is probable that, even though they would have liked to teach, they experience difficult and discomfort in teaching most of the key sexuality education topics. It is important to teach and send across clear messages to adolescents from a young age and throughout secondary and higher learning on sensitive sexual matters, also to build capacity of their teachers with the correct and up-to-date knowledge as well as the confidence to teach. As peers are the typical source of information on sexual matters, it is unclear how well-informed they are and how reliable is the information shared. Sexual practices and behaviors being largely influenced by peers is directly related to the circle of information one is in. It is therefore important to invest on availability of comprehensive SRH information among adolescents and young adults within schools and their surrounding communities so as to make the information they share credible.

Nearly half of the participants reported receiving SRE while at University. In Tanzania, implementation of health education and awareness campaigns in HLIs are compromised either due to lack of policies and staff commitment or financial prospects (41). Funding for such activities is mainly from external sources and often sexual health education programs are not streamlined (41). This has an effect on the quality of the health services or educational packages, and students find them repetitive and lacking creativity. At HLIs, there have been reports on a dearth of SRH initiatives and if present, there are concerns on their quality. Health education campaigns being labeled and perceived as "boring", "repetitive" or "normal"; and senior staff members lack commitment to SRH matters (41). Students in HLIs are generally young adults within the defined STI/HIV high-risk group of 15-24 year olds, probably at their peak years of sexual

Page 5/9 
activity, sexuality curiosities and experimentation; and many are "free" of immediate parental supervision. Studies have shown that while majority of students believe that they are at low or no risk to STIS/HIV, they were actually found to be at high risk after assessing their sexual behavior practices (6). Regional and district health management teams could be engaged to assist HLIs with regard to health promotion and targeted health awareness campaigns to minimize students' sexual health risks.

\section{Study Limitations}

Our study findings may have been biased from recalling past experiences, especially those of a sexual nature which were unpleasant. Also, this crosssectional study did not assess other family factors which may have an influence towards parent- child communication. The level of SRE among participants was not uniform as some had received SRE starting from Primary school level.

\section{Conclusion}

Young people have a gender-biased preference when it comes to learning about SRH matters from their parents; however, such conversations seldom occur. Sexual behavior among adolescents/young people is influenced largely by familial, structural and environmental factors; and therefore, talks on sexual matters need to actively begin at the family level. Community health Information, Education and Communication (IEC) should incorporate the agenda on the urgency of building skills of parents on parent-child communication on sexual matters so as to empower them to confidently initiate and convey appropriate and sufficient sexual health information. Further, comprehensive SRH education and skills building is needed in the current school SRH curriculum in order need to meet the demand and needs of students' and teachers'.

\section{List Of Abbreviations}

HLIs - High Learning Institutions

IEC - Information, Education and Communication

MUMCo - Mzumbe University - Mbeya University College

MUST - Mbeya University of Science and Technology

ODK - Open Data Kit

OUT - Open University of Tanzania

SAUT - St. Augustine University of Tanzania

SRE - Sexual and Reproductive health Education

SRH - Sexual and Reproductive health

SSA - Sub-Saharan Africa

STI - Sexually Transmitted Infection

TCU - Tanzania Commission for Universities

TEKU - Teofilo Kisanji University (Mbeya)

TIA - Tanzania Institute of Accountancy

WHO - World Health Organization

\section{Declarations}

\section{Ethics approval and consent to participate}

Complete study information was given to all eligible participants and the ones who agreed to participate, signed an informed consent form prior to any study related activity. Ethical approval was granted by the Mbeya Medical Research and Ethics Review Committee (Reference Number SZEC-2439/R.A/V.1/07), Kilimanjaro Christian Medical College Research Ethics and Review Committee (Reference Number 2405), and National Health Research Ethics Committee (Reference Number NIMR/HQ/R.8a/Vol.IX/3092). Only participant's study identification number was used in the questionnaire; and only the Principal Investigator and Research Assistant had access to information linking the study identification number and participant's identifier.

\section{Consent for publication}

Not applicable. 


\section{Availability of data and materials}

The datasets generated and analysed during the current study are available at Figshare: Where and how do young people like to get their Sexual and Reproductive health information? https://doi.org/10.6084/m9.figshare.13049951

This study contains the following underlying data:

- Data file 1 (Dataset)

- Data file 2 (Dataset variables key)

\section{Competing Interests}

The authors declare that they have no competing interests.

\section{Funding}

This work was funded through the DELTAS Africa Initiative grant \# DEL-15-011 to THRiVE-2. The DELTAS Africa Initiative is an independent funding scheme of the African Academy of Sciences (AAS)'s Alliance for Accelerating Excellence in Science in Africa (AESA) and supported by the New Partnership for Africa's Development Planning and Coordinating Agency (NEPAD Agency) with funding from the Wellcome Trust grant \# 107742/Z/15/Z and the UK government. The views expressed in this publication are those of the author(s) and not necessarily those of AAS, NEPAD Agency, Wellcome Trust or the UK government.

The funding body had no role in the design of the study, data collection and analysis, interpretation of data or manuscript writing.

\section{Authors' Contributions}

RDM collected, analyzed, interpreted the participant data and was a major contributor in writing this manuscript. PM and SEM supervised the work, reviewed and edited the manuscript. All authors read and approved the final manuscript.

\section{Acknowledgments}

All students who participated in the study and the Participant recruitment team (Matilda Paul, Jerry Kapungu, Clara Geofrey, Fadhili Mwakyusa).

\section{References}

1. Ali M, Farron M, Ouedraogo L, Mahaini RK, Miller K, Kabra R. Research gaps and emerging priorities in sexual and reproductive health in Africa and the Eastern Mediterranean regions. Reprod Health [Internet]. 2018 Dec 5;15(1):39. Available from: https://reproductive-healthjournal.biomedcentral.com/articles/10.1186/s12978-018-0484-9

2. WHO. Sexually transmitted infections (STIs): key facts [Internet]. WHO. 2016 [cited 2020 Apr 2]. p. 1-10. Available from: http://www.who.int/mediacentre/factsheets/fs110/en/

3. UNAIDS. The Gap Report [Internet]. 2014 [cited 2018 Feb 2]. Available from: http://files.unaids.org/en/media/unaids/contentassets/documents/unaidspublication/2014/UNAIDS_Gap_report_en.pdf

4. Tanzania HIV and Malaria Indicator Survey. THMIS 2011-12 Key Findings [Internet]. p. pg 109. Available from: https://www.nbs.go.tz/index.php/en/census-surveys/health-statistics/hiv-and-malaria-survey/89-thmis-2011-12-key-findings

5. Tanzania Commission for AIDS, Zanzibar AIDS Commission. Tanzania HIV Impact Survey (THIS) 2016-2017: Final report. Dar es Salaam.

6. Rutherford GW, Anglemyer A, Bagenda D, Muyonga M, Lindan CP, Barker JL, et al. University students and the risk of HIV and other sexually transmitted infections in Uganda: The crane survey. Int J Adolesc Med Health. 2014;26(2):209-15.

7. De Paula, A., Shapira G. and Todd PE. How Beliefs about HIV Affect Risky Behaviors: Evidence from Malawi. J Appl Econom. 2014;29(6):944-64.

8. Wight D, Plummer M, Ross D. The need to promote behaviour change at the cultural level: one factor explaining the limited impact of the MEMA kwa Vijana adolescent sexual health intervention in rural Tanzania. A process evaluation. BMC Public Health [Internet]. 2012 Dec 14;12(1):788. Available from: http://bmcpublichealth.biomedcentral.com/articles/10.1186/1471-2458-12-788

9. Kirby D, Laris BA, Rolleri L. Impact of Sex and HIV Education Programs on Sexual Behaviors of Youth in Developing and Developed Countries. [Internet]. New York; 2005. Report No.: WP05-03. Available from:

https://www.researchgate.net/publication/237371707_Impact_of_Sex_and_HIV_Education_Programs_on_Sexual_Behaviors_of_Youth_in_Developing_and

10. Mueller TE, Gavin LE, Kulkarni A. The Association Between Sex Education and Youth's Engagement in Sexual Intercourse, Age at First Intercourse, and Birth Control Use at First Sex. J Adolesc Heal [Internet]. 2008 Jan;42(1):89-96. Available from:

https://linkinghub.elsevier.com/retrieve/pii/S1054139X07003254

11. Kapinga OS, Hyera DF. Pupils' Perceptions of Sex and Reproductive Health Education in Primary Schools in Tanzania: A phenomenological study. J Educ Pract. 2015;6(No.6). 
12. Mkumbo KA. Teachers' Attitudes towards and comfort about teaching School-Based Sexuality Education in Urban and Rural Tanzania. Glob J Health Sci [Internet]. 2012;4(4):149-58. Available from: http://www.ccsenet.org/journal/index.php/gjhs/article/view/17168

13. Obasi Al, Cleophas B, Ross DA, Chima KL, Mmassy G, Gavyole A, et al. Rationale and design of the MEMA kwa Vijana adolescent sexual and reproductive health intervention in Mwanza Region, Tanzania. AIDS Care [Internet]. 2006 May 18;18(4):311-22. Available from: https://www.tandfonline.com/doi/full/10.1080/09540120500161983

14. Mkumbo KA. Content analysis of the status and place of sexuality education in the national school policy and curriculum in Tanzania. Educ Res Rev. 2009;4(12):616-25.

15. Ross DA, Changalucha J, Obasi Al, Todd J, Plummer ML, Cleophas-Mazige B, et al. Biological and behavioural impact of an adolescent sexual health intervention in Tanzania: a community-randomized trial. AIDS [Internet]. 2007 Sep;21(14):1943-55. Available from: http://journals.Iww.com/00002030200709120-00014

16. Markham CM, Lormand D, Gloppen KM, Peskin MF, Flores B, Low B, et al. Connectedness as a predictor of Sexual and Reproductive Health outcomes for youth. J Adolesc Heal [Internet]. 2010 Mar;46(3):S23-41. Available from: https://linkinghub.elsevier.com/retrieve/pii/S1054139X09006387

17. Shoop DM, Davidson PM. AIDS and adolescents: the relation of parent and partner communication to adolescent condom use. J Adolesc [Internet]. 1994 Apr;17(2):137-48. Available from: https://linkinghub.elsevier.com/retrieve/pii/S0140197184710141

18. Mmbaga EJ, Leonard F, Leyna GH. Incidence and Predictors of Adolescent's Early Sexual Debut after three decades of HIV interventions in Tanzania: A Time to Debut Analysis. Sullivan PS, editor. PLoS One [Internet]. 2012 Jul 27;7(7):e41700. Available from:

https://dx.plos.org/10.1371/journal.pone.0041700

19. Kajula LJ, Sheon N, De Vries H, Kaaya SF, Aarø LE. Dynamics of Parent-Adolescent Communication on Sexual Health and HIV/AIDS in Tanzania. AIDS Behav [Internet]. 2014 Jan 8;18(S1):69-74. Available from: http://link.springer.com/10.1007/s10461-013-0634-6

20. Namisi FS, Flisher AJ, Overland S, Bastien S, Onya H, Kaaya S, et al. Sociodemographic variations in communication on sexuality and HIV/AIDS with parents, family members and teachers among in-school adolescents: A multi-site study in Tanzania and South Africa. Scand J Public Health [Internet]. 2009 Jun 3;37(2_suppl):65-74. Available from: http://journals.sagepub.com/doi/10.1177/1403494808086986

21. Moser AM, Reggiani B UA. Risky sexual behavior among university students. Rev Assoc Med Bras. 2007;53(2):116-21.

22. Bilinga, M., Mabula N. Teaching sexuality education in primary schools in Tanzania: challenges and implications. J Educ Pract. 2014;5(27):21-30.

23. Mkumbo KA. Students' attitudes towards school-based sex and relationships education in Tanzania. Health Educ J [Internet]. 2014;73(6):642-56. Available from: https://doi.org/10.1177/0017896913510426

24. Mkumbo KA. What Tanzanian young people want to know about sexual health: implications for school-based sex and relationships education. Sex Educ [Internet]. 2010 Nov;10(4):405-12. Available from: http://www.tandfonline.com/doi/abs/10.1080/14681811.2010.515097

25. Adeyoyin So. Use of Reproductive Health Information among University Undergraduates in Ogun State, Nigeria. Int J Knowl Content Dev Technol. 2017;7(3):49-65.

26. McCauley AP, Salter C, Kiragu K, Senderowitz J. Meeting the needs of young adults. Popul Rep J [Internet]. 1995 Oct;(41):1-43. Available from: http://www.ncbi.nlm.nih.gov/pubmed/8654883

27. Wamoyi J, Fenwick A, Urassa M, Zaba B, Stones W. Parent-child communication about sexual and reproductive health in rural Tanzania: Implications for young people's sexual health interventions. Reprod Health [Internet]. 2010 Dec 12;7(1):6. Available from: https://reproductive-healthjournal.biomedcentral.com/articles/10.1186/1742-4755-7-6

28. Bastien S, Kajula L, Muhwezi W. A review of studies of parent-child communication about sexuality and HIV/AIDS in sub-Saharan Africa. Reprod Health [Internet]. 2011 Dec 24;8(1):25. Available from: http://reproductive-health-journal.biomedcentral.com/articles/10.1186/1742-4755-8-25

29. Svanemyr J, Amin A, Robles OJ, Greene ME. Creating an enabling environment for adolescent sexual and reproductive health: A framework and promising approaches. J Adolesc Heal [Internet]. 2015;56(1):S7-14. Available from: http://dx.doi.org/10.1016/j.jadohealth.2014.09.011

30. Muyinda H, Nakuya J, Pool R, Whitworth J. Harnessing the senga institution of adolescent sex education for the control of HIV and STDs in rural Uganda. AIDS Care [Internet]. 2003 Apr 27;15(2):159-67. Available from: https://www.tandfonline.com/doi/full/10.1080/0954012031000068308

31. Izugbara CO. Home-Based Sexuality Education. Youth Soc [Internet]. 2008 Jun 9;39(4):575-600. Available from: http://journals.sagepub.com/doi/10.1177/0044118X07302061

32. Merluzzi, TV., Nairn RC. Adulthood and aging: Transitions in health and health cognition. In: Whitman, TL. , Merluzzi, TV., Robert WD, (Editor). Life-Span Perspectives On Health And IIIness. London: Lawrence Erlbaum Associates Publishers; 1999. p. 189-206.

33. Msoka E. Chapter 5. In: Awortwi, N., Musahara H, (Editor). Implementation of the Millennium Development Goals: Progresses and Challenges in some African Countries. illustrate. OSSREA, 2016; 2016.

34. Cardoso JC, Mwolo MP. Assessment of non-formal sexual education strategies for adolescent girls: the case of Tanzania. Ens Avaliação e Políticas Públicas em Educ [Internet]. 2017;25(95):527-47. Available from: http://www.scielo.br/scielo.php?script=sci_arttext\&pid=S010440362017000200527\&lng=en\&tlng=en

35. World Health Organisation. Global health sector strategy on sexually transmitted infections 2016-2021: Towards ending STIs [Internet]. [cited 2017 Feb 27]. Available from: http://apps.who.int/iris/bitstream/10665/246296/1/WHO-RHR-16.09-eng.pdf?ua=1

36. Sani AS, Abraham C, Denford S, Ball S. School-based sexual health education interventions to prevent STI/HIV in sub-Saharan Africa: a systematic review and meta-analysis. BMC Public Health [Internet]. 2016 Dec 10;16(1):1069. Available from:

http://bmcpublichealth.biomedcentral.com/articles/10.1186/s12889-016-3715-4 
37. Fonner VA, Armstrong KS, Kennedy CE, O’Reilly KR, Sweat MD. School Based Sex Education and HIV Prevention in Low- and Middle-Income Countries: A Systematic Review and Meta-Analysis. Vermund SH, editor. PLoS One [Internet]. 2014 Mar 4;9(3):e89692. Available from:

https://dx.plos.org/10.1371/journal.pone.0089692

38. Paul-Ebhohimhen VA, Poobalan A, van Teijlingen ER. A systematic review of school-based sexual health interventions to prevent STI/HIV in sub-Saharan Africa. BMC Public Health [Internet]. 2008 Dec 7;8(1):4. Available from: http://bmcpublichealth.biomedcentral.com/articles/10.1186/1471-2458-8-4

39. Kawai K, Kaaya SF, Kajula L, Mbwambo J, Kilonzo GP, Fawzi WW. Parents' and teachers' communication about HIV and sex in relation to the timing of sexual initiation among young adolescents in Tanzania. Scand J Public Health [Internet]. 2008 Nov;36(8):879-88. Available from: http://journals.sagepub.com/doi/10.1177/1403494808094243

40. Gallant M, Maticka-Tyndale E. School-based HIV prevention programmes for African youth. Soc Sci Med [Internet]. 2004 Apr;58(7):1337-51. Available from: http://linkinghub.elsevier.com/retrieve/pii/S0277953603003319

41. EAC/EALP. HIV Sero-Behavioural Study in Six Universities in Tanzania. [Internet]. 2010. Available from: http://tacaidslibrary.go.tz/bitstream/handle/123456789/82/TANZANIA UNIVERSITIES HIV STUDY REPORT.pdf?sequence=1

\section{Tables}

Due to technical limitations, table 1, Table 2 and Table 3 are only available as a download in the Supplemental Files section.

\section{Figures}

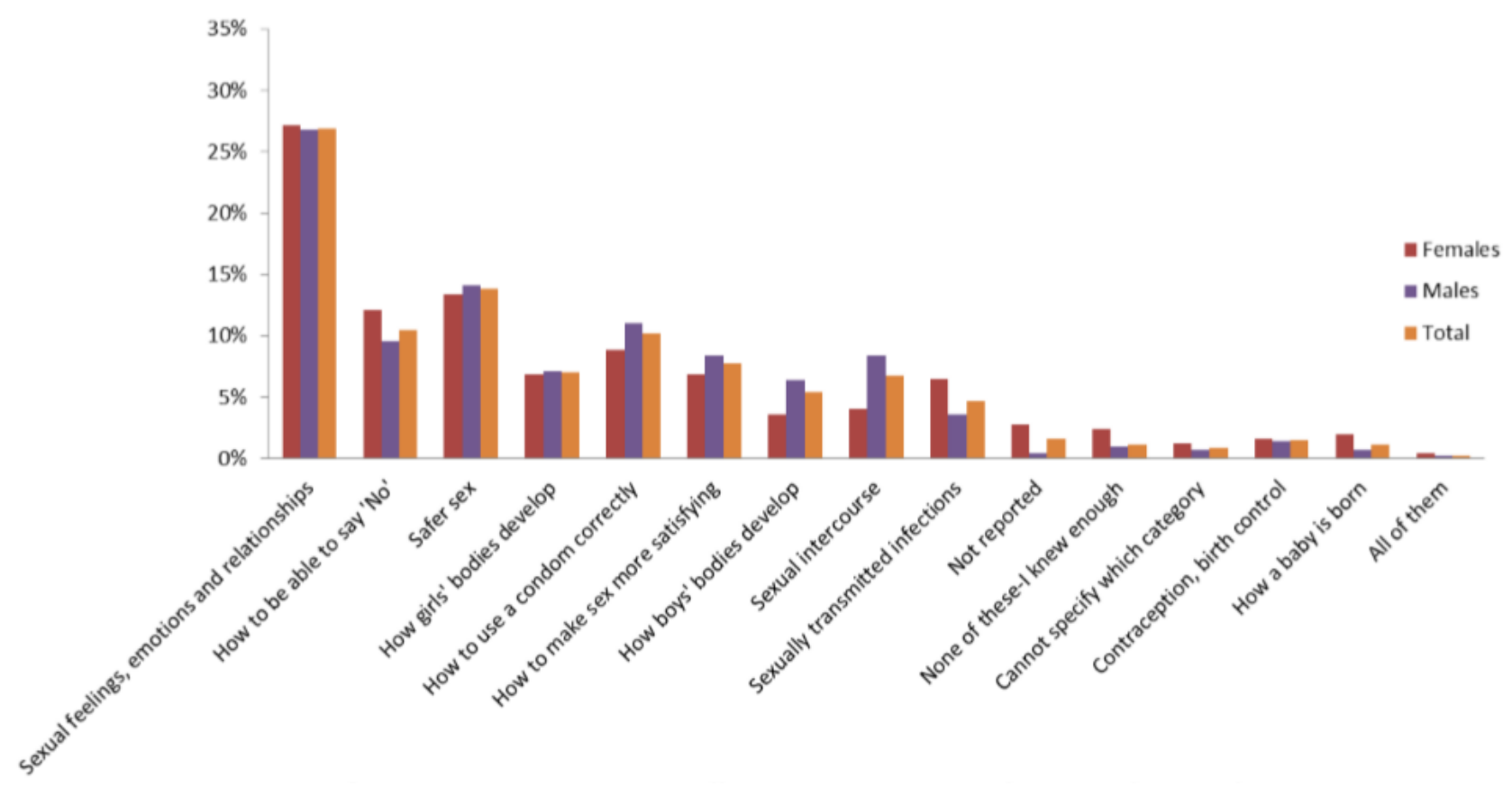

Figure 1

SRH Information gap among sexually active participants during yearly sexual experience.

\section{Supplementary Files}

This is a list of supplementary files associated with this preprint. Click to download.

- Table13.pdf

- AppendixB1Selfadministeredquestionnaire.pdf

- STROBEchecklistRubyMcharo.doc 